Bond University

Research Repository

\title{
Rehabilitation characteristics and patient barriers to and facilitators of ACL reconstruction rehabilitation: A cross-sectional survey
}

Walker, Adam; Hing, Wayne; Lorimer, Anna; Rathbone, Evelyne

Published in:

Physical Therapy in Sport

DOI:

10.1016/j.ptsp.2021.01.001

Licence:

CC BY-NC-ND

Link to output in Bond University research repository.

Recommended citation(APA):

Walker, A., Hing, W., Lorimer, A., \& Rathbone, E. (2021). Rehabilitation characteristics and patient barriers to and facilitators of ACL reconstruction rehabilitation: A cross-sectional survey. Physical Therapy in Sport, 48, 169-176. https://doi.org/10.1016/j.ptsp.2021.01.001

\section{General rights}

Copyright and moral rights for the publications made accessible in the public portal are retained by the authors and/or other copyright owners and it is a condition of accessing publications that users recognise and abide by the legal requirements associated with these rights.

For more information, or if you believe that this document breaches copyright, please contact the Bond University research repository coordinator. 
2 Objectives To investigate patient-reported rehabilitation characteristics and barriers to and

3 facilitators of $A C L$ reconstruction rehabilitation.

$4 \quad$ Design Survey-based study.

$5 \quad$ Setting Online survey platform.

$6 \quad$ Participants Adults 1-20 years post ACL reconstruction ( $n=304)$.

7 Main Outcome Measures 1) rehabilitation characteristics, 2) barriers to and facilitators of

8 rehabilitation.

9 Results Fear of re-injury (43.8\%) was the highest rating barrier to rehabilitation adherence,

10 while a good relationship with your rehabilitation provider was regarded as the most

11 important factor (83.6\%) in facilitating rehabilitation. Rehabilitation frequency reduced across

12 the duration of rehabilitation from most commonly $1 \times$ week $(38.2 \%)$ in the first three months

13 to once every month (26\%) from 6-9 months. Almost all participants $(95.7 \%)$ consulted a

14 rehabilitation provider for the first six months. Only $43.4 \%$ of respondents returned to their

15 previous level of sport. The exploratory analysis identified that low barriers to rehabilitation

16 and a longer duration of supervised rehabilitation are associated with a faster return to sport,

17 greater likelihood of return to previous level of sport and fewer reported ongoing problems

18 with the knee.

19 Conclusions This cross-sectional survey provides insight into the patient's experience of

20 rehabilitation practices and a patient's perspective on the key barriers to and facilitators of

21 ACL rehabilitation adherence and participation.

22 Keywords physiotherapy, return to sport, adherence, compliance 
24 In a sporting context, one in 29 female athletes and one in 50 male athletes will rupture their anterior cruciate ligament ( $A C L)$ (1). Reconstruction and subsequent rehabilitation following injury is still considered the primary treatment method (2). Unfortunately, outcomes following ACL reconstruction are still reported as sub-optimal (3) as many athletes fail to return to their previous level of sport (4), have ongoing pain and disability (5) or reinjure the same or contralateral knee upon return to sport (6). Incomplete rehabilitation has been reported to be one of the main factors contributing to suboptimal outcomes after $\mathrm{ACL}$ reconstruction (7). Research shows that only $30 \%$ of patients complete rehabilitation beyond three months, with only $5 \%$ following evidence-based recommendations (8). Recent evidence has demonstrated an increased likelihood of returning to sport and meeting discharge criteria with a longer duration of supervised physiotherapy (8, 9). Furthermore, patients that return to sport have been shown to have a greater long-term quality of life (10) and are less likely to reinjure if they meet discharge criteria (11).

$\mathrm{ACL}$ rehabilitation is a long-term commitment, and there can be a host of reasons why patients may not complete rehabilitation or return to sport. A recent scoping review identified personal, environmental and treatment-related factors which the individual may encounter throughout their rehabilitation, highlighting the need for patient involvement in the rehabilitation process to identify, manage and optimise care (12). As such, it is pertinent to seek the opinion of our patients as to what they find most challenging and most important during the rehabilitation process. barriers to and facilitators of rehabilitation participation and adherence in an adult population 
within the context of key patient outcomes. We aim to provide guidance to practitioners to improve rehabilitation delivery and gain information to guide future research.

\section{METHODS}

Survey Development

The design followed a seven-step process for survey scale design (13), supported by literature on recommended practices for the conduct and reporting of survey research (14). The primary author (AW) developed a 36-item web-based survey guided by the results from a recent scoping review evaluating the influence, barriers to and facilitators of adherence and participation to ACL rehabilitation completed by the authors (12) and collaboration with the research team and clinical physiotherapists who have an interest in $\mathrm{ACL}$ rehabilitation.

The preliminary questions were tested by the authors and three external researchers and clinicians for clarity, format and usability. The survey was piloted with five patients in the form of cognitive interviews (13) with the lead author for immediate feedback resulting in modifications. The second round of pilot testing was completed with six participants and final modifications made to the survey. It was determined that the survey took approximately 10 minutes to complete.

\section{Survey Instrument}

The voluntary, anonymous survey was conducted on the secure online program Qualtrics XM (www.qualtrics.com). Participants were initially presented with the 'Participant Information' section detailing the background, purpose, risks and data usage. Access to the survey was granted after the participant answered 'yes' to informed consent and two subsequent questions to ensure participant eligibility. It was stated that the survey had been developed 
only for participants 18 years and older who were at least 12 months post ACL operation but not more than 20 years ago. Participants were ineligible after 20 years as it was deemed that rehabilitation practices significantly changed since the year 2000 (15). It was clearly stated that those who had suffered an $A C L$ injury but did not have a reconstruction were ineligible.

Respondents were asked to answer questions based on their experience of rehabilitation since the time of most recent injury. The survey contained five sections; (1) demographics (Q5-8), (2) injury and surgery (Q9-14), (3) barriers to and facilitators of rehabilitation (Q15-18), (4) rehabilitation (Q19-23) and (5) return to sport (Q24-36). The complete survey instrument is available in appendix 1.

The survey utilised display logic which facilitated only the display of questions which were relevant to the respondents based on their previous responses. This ensured accurate completion of the survey and time efficiency. The total number of questions may vary between respondents. Only one question was displayed per page, and participants had to enter a response before proceeding. Respondents were permitted to go back and edit prior responses and could enter multiple answers for questions 13,20, 35 and 36. Questions 16 and 18 provided the opportunity for respondents to enter a text response, and a 5-point Likert scale was utilised in questions 15, 17, 19, 23 and 34 (13).

\section{Survey distribution}

The survey was distributed by email to local physiotherapy practices, surgical and physiotherapy patient databases, state and regional sporting clubs and associations, news articles, and through social media profiles of the authors. The email contained a summary poster, a brief overview of the study, eligibility criteria and a custom link to complete the survey instrument on Qualtrics. Anybody who received the email was free to and encouraged to share the poster and information with their contacts to increase survey reach. Survey 
responses were collected between 6 March and 15 July 2020. The study was approved by the Bond University Human Research Ethics Committee (AW02850).

\section{Data Synthesis}

The reporting of data followed the Checklist for Reporting Results of Internet E-Surveys

97 (CHERRIES) and the Strengthening the Reporting of Observational Studies in Epidemiology

98 (STROBE) statement. Following the closure of the survey, the data were screened, and responses excluded if it was incomplete, deemed to be not consistent with a valid response (submitted in less than four minutes) or was not a unique response (duplicate IP addresses). Data were then exported to the software package SPSS Statistics for Windows, version 26.0 (SPSS Inc., Armonk, NY, USA) where the data could be analysed. All responses were equally weighted.

Descriptive statistics were used to summarise the distributions for continuous variables, and the frequencies and percentages for categorical responses. Cronbach's alpha test was performed on the multi-item questions 15 and 17 to ensure internal consistency reliability. Prior to further exploratory analyses, selected variables with either multiple ordinal responses or on a continuous scale were re-categorised into binary variables, including the main variables rehabilitation (high/low) and duration of rehabilitation duration (long/short). The chi-square test was used to test for associations or differences in proportions of responses between pairs of categorical variables. Analyses were carried out in SPSS version 26, and significance values were set at $p<0.05$. 
116 A total of 413 participants responded to the survey; 304 responses were deemed eligible for

117 inclusion in the analysis. Responses were excluded for the following reasons: 81 responses

118 were incomplete, and 28 did not meet eligibility criteria. The completion rate of the survey

119 was $79 \%$.

\section{Respondent demographics}

121 Table 1 details the demographics of the respondents. The median participant age was 25 years

122 old at the time of most recent reconstruction, $58.6 \%(n=178)$ were female, $91.4 \%(n=278)$ resided in Australia, and $70.4 \%$ lived in a metropolitan area.

Table 1 - Respondent demographics $(N=304)$

\begin{tabular}{llll}
\hline Participant characteristic & $\boldsymbol{n}(\%)$ & Injury characteristic & $\boldsymbol{n}$ (\%) \\
\hline Age, median (IQR) & & Second injury & $65(21.4)$ \\
\hline At time of survey & $32(26.0-40.0)$ & Ipsilateral injury & $21(32.3)$ \\
\hline At time of reconstruction & $25(21.0-32.8)$ & Contralateral injury & $44(67.7)$ \\
\hline Gender & & Associated injuries & $225(74.0)$ \\
\hline Male & $126(41.4)$ & Meniscus injury & $171(56.3)$ \\
\hline Female & $178(58.6)$ & Medial collateral ligament & $81(26.6)$ \\
\hline Country & Lateral collateral ligament & $26(8.6)$ \\
\hline Australia & $278(91.4)$ & Posterior cruciate ligament & $31(10.2)$ \\
\hline International & Cartilage injury & $58(19.1)$ \\
\hline Area profile & $26(8.6)$ & Fracture & $23(7.6)$ \\
\hline Metropolitan & Graft & $261(82.2)$ \\
\hline Regional/Rural & Hamstring tendon & $35(11.1)$ \\
\hline & $214(70.4)$ & Patella tendon & $13(4.1)$ \\
\hline & $90(29.6)$ & Quadriceps tendon & $3(0.9)$ \\
\hline & Allograft \\
\hline
\end{tabular}


132 Table 2 details the responses to questions in the survey relating to the respondent's

133 rehabilitation. Respondents were most likely to participate in rehabilitation with a

134 physiotherapist (97.4\%) in a private clinic (83.9\%), and rehabilitation was deemed essential by

$13587.8 \%$ of participants. The majority of participants were extremely satisfied (38.8\%) or quite

136 satisfied (37.2\%) with the care delivered by their rehabilitation provider. Only $3.6 \%$ of

137 participants reported being not at all satisfied with their care. These results were in line with

138 overall satisfaction after $\mathrm{ACL}$ reconstruction with $34.5 \%$ stating they are extremely satisfied

139 and $36.5 \%$ quite satisfied, despite $79.6 \%$ of respondents reporting ongoing problems with their 140 knee.

\begin{tabular}{|c|c|c|c|}
\hline Characteristic & $n(\%)$ & Characteristic & $n(\%)$ \\
\hline Rehabilitation providers & \multicolumn{3}{|c|}{ Rehabilitation provider satisfaction } \\
\hline Physiotherapist & $296(97.4)$ & Extremely satisfied & $118(38.8)$ \\
\hline I did my own rehabilitation & $64(21.2)$ & Quite satisfied & $113(37.2)$ \\
\hline Strength and Conditioning Coach & $42(13.8)$ & Moderately satisfied & $50(16.4)$ \\
\hline Personal Trainer & $31(10.2)$ & Slightly satisfied & $12(3.9)$ \\
\hline Exercise Physiologist & $28(9.5)$ & Not at all satisfied & $11(3.6)$ \\
\hline Athletic Trainer & $11(3.6)$ & Outcome satisfaction & \\
\hline Rehabilitation environment & & Extremely satisfied & $105(34.5)$ \\
\hline Private clinic & 255 (83.9) & Quite satisfied & $111(36.5)$ \\
\hline Gym or fitness facility & 94 (30.9) & Moderately satisfied & $60(19.7)$ \\
\hline Hospital clinic & $62(20.4)$ & Slightly satisfied & $16(5.3)$ \\
\hline Sports team & $41(13.5)$ & Not at all satisfied & $12(3.9)$ \\
\hline School & $7(2.3)$ & Ongoing knee problems & \\
\hline Rehabilitation importance & & Significant problems & $16(5.3)$ \\
\hline Essential & $267(87.8)$ & Moderate problems & $43(14.1)$ \\
\hline Quite important & $31(10.2)$ & Minor problems & $183(60.2)$ \\
\hline Moderately important & $3(1.0)$ & No problems & $62(20.4)$ \\
\hline Slightly important & $2(0.7)$ & & \\
\hline Not important & $1(0.3)$ & & \\
\hline
\end{tabular}




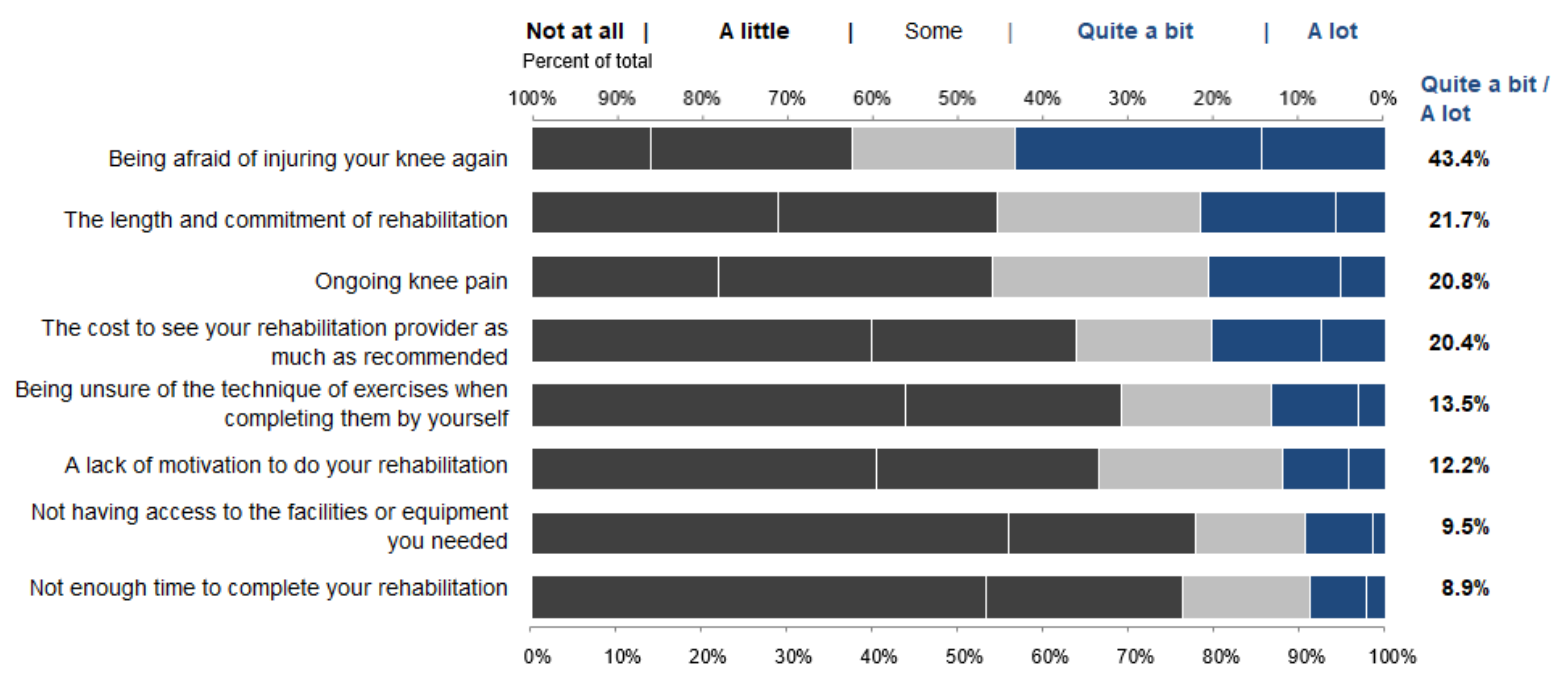

151

Figure 1. Barriers to completing recommended rehabilitation ordered from most to least affecting rehabilitation, using the percentage of negative responses 'Quite a lot' and 'A lot'. Note: The percentage for each response can be approximated using the percent of total bars at the top or bottom of the figure.

\section{Facilitators of rehabilitation}

Figure 2 presents which factors the respondents deemed important in facilitating their rehabilitation. Cronbach's alpha (0.80) demonstrated good internal consistency of the question. The majority of factors presented to the participants were rated as important to rehabilitation. A good relationship with your rehabilitation provider was regarded as the most 


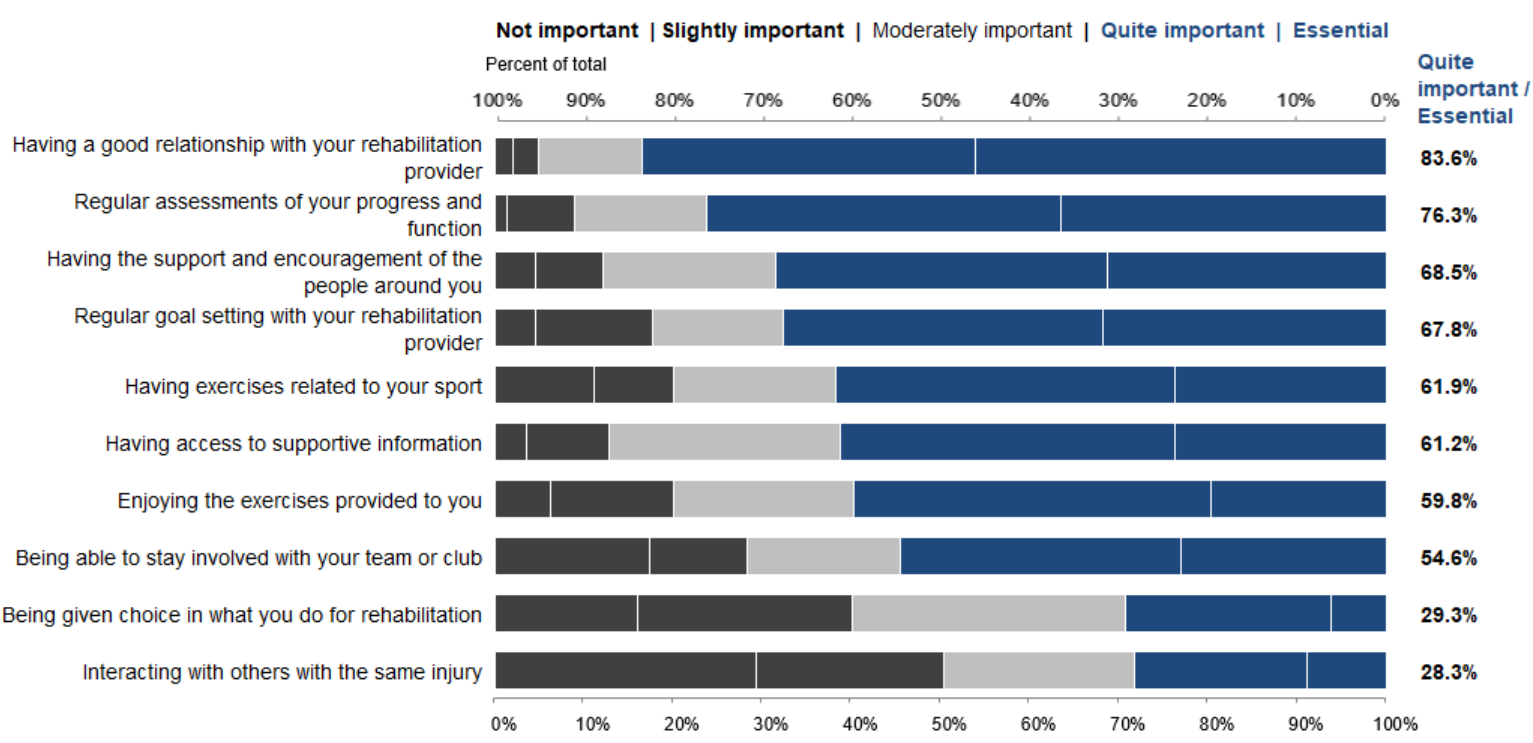

Figure 2. Facilitators to completing recommended rehabilitation, ordered from most to least important, using the percentage of 'Quite important' and 'Essential' responses. Note: The percentage for each response can be approximated using the percent of total bars at the top or bottom of the figure.

\section{Rehabilitation frequency and duration}

173 Figure 3 presents the most common frequency of consultation with a rehabilitation provider per post-operative time period. A clear trend can be seen of reducing rehabilitation frequency across the duration of rehabilitation from most commonly once a week $(38.2 \%)$ in the first three months, every two weeks (29.9\%) at 3-6 months and once every month (26\%) at 6-9 months. Almost all participants (95.7\%) consulted a rehabilitation provider for the first six 

and $63.2 \%$ from 12 months.

\begin{tabular}{|c|c|c|c|c|c|c|c|c|}
\hline & \multicolumn{7}{|c|}{ Rehabilitation frequency } \\
\hline & & $>2$ times/week & 2 times/week & Once a week & Every 2 weeks & $\begin{array}{l}\text { Once every } \\
\text { month }\end{array}$ & $\begin{array}{l}\text { Less than } \\
\text { once a month }\end{array}$ & $\begin{array}{l}\text { I did not see } \\
\text { anyone }\end{array}$ \\
\hline \multirow{5}{*}{ 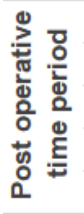 } & First 3 months & $13.5 \%$ & $20.4 \%$ & $38.2 \%$ & $21.4 \%$ & $3.6 \%$ & $1.6 \%$ & $1.3 \%$ \\
\hline & 3-6 months & $5.9 \%$ & $9.5 \%$ & $21.7 \%$ & $29.9 \%$ & $22.0 \%$ & $6.6 \%$ & $4.3 \%$ \\
\hline & 6-9 months & $4.3 \%$ & $3.6 \%$ & $9.9 \%$ & $17.4 \%$ & $26.0 \%$ & $17.8 \%$ & $21.1 \%$ \\
\hline & 9-12 months & $3.0 \%$ & $1.6 \%$ & $7.2 \%$ & $8.2 \%$ & $18.1 \%$ & $22.7 \%$ & $39.1 \%$ \\
\hline & 12 months+ & $1.6 \%$ & $0.7 \%$ & $4.6 \%$ & $2.6 \%$ & $8.2 \%$ & $19.1 \%$ & $63.2 \%$ \\
\hline
\end{tabular}

Figure 3. Heat map of reported rehabilitation frequency per post-operative time frame. Note: the darkest cells have the highest percentages per row, representing the most commonly reported responses; aggregate percentages equate to 100 in each row.

Table 3 details the responses to questions in the survey relating to the respondent's sports participation pre and post-injury or surgery. Prior to surgery, $86.5 \%$ of respondents aimed to return to their previous level of sport, however, only $43.4 \%$ of respondents achieved this postsurgery, and $14.2 \%$ did not return to any knee strenuous sport. Both the level, as defined by Grindem et al. (2014) (16), and the frequency of knee-strenuous sport also decreased postsurgery.

Respondents expectations of when they would be able to return to their previous level of sport and when they did return to sport were consistent with each other. Over $70 \%$ of respondents returned to sport between $9-12$ months (33.5\%) and $12-18$ months (37.6\%) postsurgery. Only $12 \%$ of respondents returned to sport prior to 9 months. Knee related problems changed sports (78.0\%). 
Table 3 Sports participation and outcomes

\begin{tabular}{|c|c|c|}
\hline Characteristic & $n(\%)$ & $n(\%)$ \\
\hline Return to competitive level of sport & Pre-surgery aim & Post-surgery \\
\hline Previous competitive level & $263(86.5)$ & $132(43.4)$ \\
\hline Lower level of competition & - & $88(28.9)$ \\
\hline Changed sports & - & $41(13.5)$ \\
\hline Did not return to sport & - & $43(14.2)$ \\
\hline Level of knee strenuous sport & Pre-injury & Post-surgery \\
\hline $\begin{array}{l}\text { Level } 1 \text { - Jumping, hard pivoting and } \\
\text { cutting }\end{array}$ & $270(88.8)$ & $197(64.8)$ \\
\hline Level 2 - Running twisting and turning & $25(8.2)$ & $36(11.8)$ \\
\hline Level 3 - No twisting, turning or jumping & $4(1.3)$ & $28(9.2)$ \\
\hline $\begin{array}{l}\text { Level } 4 \text { - No knee strenuous sport / Did } \\
\text { not return to sport }\end{array}$ & $5(1.6)$ & $43(14.2)$ \\
\hline Sport participation frequency per week & Pre-injury & Post-injury \\
\hline$>5$ & $48(15.8)$ & $23(7.6)$ \\
\hline $4-5$ & $91(29.9)$ & $64(21.1)$ \\
\hline $2-3$ & $136(44.7)$ & $136(44.7)$ \\
\hline $0-1$ & $24(7.9)$ & $38(12.5)$ \\
\hline Return to sport timeframe & Pre-surgery expectation & Post-surgery \\
\hline 3-6 months & $7(2.3)$ & $8(3.0)$ \\
\hline 6-9 months & $41(13.5)$ & $24(9.0)$ \\
\hline 9-12 months & $124(40.8)$ & 89 (33.5) \\
\hline $12-18$ months & $106(34.9)$ & $100(37.6)$ \\
\hline 18-24 months & $7(2.3)$ & $24(9.0)$ \\
\hline 2 years or longer & $19(6.3)$ & $21(7.9)$ \\
\hline $\begin{array}{l}\text { Reason for change in post-surgery sports } \\
\text { competition level }\end{array}$ & Non-knee related problems & Knee related problems \\
\hline Lower level of competition & $29(33.0)$ & $59(67.0)$ \\
\hline Changed sports & $9(22.0)$ & $32(78.0)$ \\
\hline Return to sport decision making & Who was involved & Who should be involved \\
\hline Rehabilitation provider & $214(70.4)$ & $277(91.1)$ \\
\hline The individual & $234(77)$ & $233(76.6)$ \\
\hline Surgeon & $145(47.7)$ & $198(65.1)$ \\
\hline Family and friends & $70(23)$ & $67(22)$ \\
\hline Coach & $37(12.2)$ & $58(19.1)$ \\
\hline
\end{tabular}


Exploratory chi-square analyses were performed to evaluate any difference in the distribution

of responses across various variables which include binary variables as presented in Table 4.

Significant differences in the distribution of responses were demonstrated between the three

212 (Table 5).

214 Table 4. Summary statistics for variables re-categorised into binary variables before chi-square analyses

\begin{tabular}{ll}
\hline Variable & $\boldsymbol{n}(\%)$ \\
\hline Barriers to rehabilitation adherence & \\
\hline High (average 'some' or higher) & $191(62.8)$ \\
\hline Low (average 'a little' or less) & $113(37.2)$ \\
\hline Frequency of supervised rehabilitation & \\
\hline Low (<every 2 weeks) & $200(34.2)$ \\
\hline High ( $\geq$ every 2 weeks) & $104(65.8)$ \\
\hline Duration of supervised rehabilitation & \\
\hline$<9$ months & $119(39.1)$ \\
\hline$\geq 9$ months & $185(60.9)$ \\
\hline Age at reconstruction & $205(67.4)$ \\
\hline$<30$ yrs & $99(32.6)$ \\
\hline$\geq 30$ yrs
\end{tabular}

219 high, a higher percentage of people returned to sport before 12 months (47.1\% v 27.5\%), 
There was no association between high or low barriers to rehabilitation and frequency or duration of rehabilitation.

A higher percentage of respondents were extremely satisfied with their rehabilitation provider $(50.0 \%$ v $33.0 \%)$ in the group who had a high frequency of supervised rehabilitation compared to low.

In the group who attended supervised rehabilitation for greater than nine months compared to less than nine months, a higher percentage of people returned to sport ( $91.8 \%$ v $82.4 \%)$, returned to their previous level of competition (65.5\% v $47.4 \%)$, were extremely satisfied with their rehabilitation provider $(49.7 \% \vee 21.8 \%)$ and their overall outcome $(40.5 \% \vee 25.2 \%)$ and fewer reported significant or moderate ongoing problems with their knee (14.1\% v 27.8\%)

Influencing demographic factors to barriers to, frequency and duration of supervised rehabilitation

Participants who lived in a metropolitan area as opposed to living in a regional or rural location reported a higher frequency of supervised rehabilitation $(37.9 \% \vee 25.6 \%, p=0.039)$ and supervised rehabilitation duration greater than nine months ( $64.5 \%$ v $52.2 \%, p=0.046)$. In the group aged $<30$ years compared to $\geq 30$ years a higher percentage of patients reported high barriers to rehabilitation adherence $(76.1 \% \vee 23.9 \%, p=0.013)$, high frequency of supervised rehabilitation $(80.8 \%$ v $19.2 \%, p<0.001)$ and supervised rehabilitation duration greater than 9 months $(75.7 \% \vee 32.6 \%, \mathrm{p}<0.001)$. 

variables.

\begin{tabular}{lllllll}
\hline & \multicolumn{2}{l}{$\begin{array}{l}\text { Barriers to rehabilitation } \\
\text { adherence }\end{array}$} & \multicolumn{2}{l}{$\begin{array}{l}\text { Frequency of supervised } \\
\text { rehabilitation }\end{array}$} & \multicolumn{2}{l}{$\begin{array}{l}\text { Duration of supervised } \\
\text { rehabilitation }\end{array}$} \\
\cline { 2 - 6 } Outcome variable & Chi-square & $p$-value & Chi-square & $p$-value & \multicolumn{2}{l}{$\begin{array}{l}\text { Chi-square } \\
p \text {-value }\end{array}$} \\
\hline Time to return to sport & $\chi_{6}^{2}=14.86$ & $0.021^{*}$ & $\chi_{6}^{2}=11.61$ & 0.071 & $\chi_{6}^{2}=16.10$ & $0.013^{*}$ \\
\hline $\begin{array}{l}\text { Return to previous level of } \\
\text { sport }\end{array}$ & $\chi_{2}^{2}=24.16$ & $<0.001^{*}$ & $\chi_{2}^{2}=5.00$ & 0.084 & $\chi_{2}^{2}=7.40$ & $0.025^{*}$ \\
\hline Ongoing knee problems & $\chi_{3}^{2}=14.50$ & $0.020^{*}$ & $\chi_{3}^{2}=3.05$ & 0.384 & $\chi_{3}^{2}=14.50$ & $0.020^{*}$ \\
\hline $\begin{array}{l}\text { Rehabilitation provider } \\
\text { satisfaction }\end{array}$ & $\chi_{4}^{2}=32.05$ & $<0.001^{*}$ & $\chi_{4}^{2}=12.24$ & $0.016^{*}$ & $\chi_{4}^{2}=31.74$ & $<0.001^{*}$ \\
\hline Overall outcome satisfaction & $\chi_{4}^{2}=33.28$ & $<0.001^{*}$ & $\chi_{4}^{2}=2.71$ & 0.608 & $\chi_{4}^{2}=19.78$ & $0.001^{*}$ \\
\hline Interaction & & & & & & \\
\hline Barriers & - & & & & & \\
\hline Influencing variable & & & & & & \\
\hline Geographical location & $\chi_{1}^{2}=0.162$ & 0.088 & $\chi_{1}^{2}=4.255$ & $0.039^{*}$ & $\chi_{1}^{2}=4.00$ & $0.046^{*}$ \\
\hline Age at reconstruction & $\chi_{1}^{2}=6.16$ & $0.013^{*}$ & $\chi_{1}^{2}=12.80$ & $<0.001^{*}$ & $\chi_{1}^{2}=14.62$ & $<0.001^{*}$ \\
\hline Gender & $\chi_{1}^{2}=0.002$ & 0.968 & $\chi_{1}^{2}=0.581$ & 0.446 & $\chi_{1}^{2}=0.770$ & 0.380 \\
\hline Re-injury & $\chi_{1}^{2}=0.837$ & 0.360 & $\chi_{1}^{2}=1.231$ & 0.267 & $\chi_{1}^{2}=1.622$ & 0.203 \\
\hline Associated injuries & $\chi_{1}^{2}=0.829$ & 0.362 & $\chi_{1}^{2}=1.232$ & 0.267 & $\chi_{1}^{2}=0.614$ & 0.433 \\
\hline
\end{tabular}

* statistically significant result $p<0.05$

The results of this survey provide insight into the state of rehabilitation practices and the adult patients perspective on the key barriers to and facilitators of ACL rehabilitation adherence and their relationship to patient outcomes. The most important findings of this survey are that fear of re-injury, and the therapeutic relationship was the strongest factors reported by patients which influence their ability to complete rehabilitation as recommended. Most respondents (78.9\%) completed supervised rehabilitation through to 9 months post-operative, with a consistent trend of reduced supervision as rehabilitation progressed. We also reported a low 
return to previous level of sport rate of $43.4 \%$, despite $86.5 \%$ of respondents aiming to return to their previous level of sport prior to surgery.

The exploratory analyses provided further insights into associations between the level of barriers experienced by respondents, supervised rehabilitation frequency and duration and a variety of clinically important outcomes following $\mathrm{ACL}$ reconstruction. We also explored the demographic factors which may influence these variables.

\section{$\underline{\text { Rehabilitation characteristics }}$}

Our results demonstrated that patients strongly believe that appropriate rehabilitation is essential in their recovery from surgery and return to sport. Physiotherapists were reported as the primary provider of rehabilitation services, and overall satisfaction of patients following $\mathrm{ACL}$ reconstruction was closely related to satisfaction with the care delivered by their rehabilitation provider. Patients have previously described the physiotherapist's role as the coordinator, motivator and guide in the delivery of high-value evidence-based care to facilitate patient return to sport goals (17).

The severity of ongoing knee problems requires further investigation, as only $20 \%$ of respondents reported having no ongoing problems with their knee, with $20 \%$ reporting moderate or severe problems. While patient-reported outcome measures are often used in the assessment of outcome following reconstruction (18), it can be hard to ascertain the presence of ongoing pain from these studies. Further research into the presence of ongoing pain, often despite a return to sport, should be considered in the evaluation of a successful outcome after $\mathrm{ACL}$ reconstruction.

Rehabilitation providers need to consider the risk of re-injury on the contralateral limb following return to sport. The second $A C L$ injury rate in this cohort of patients was approximately $20 \%$, which is consistent with previous evidence (19); however, the risk of 
injuring the contralateral leg was twice that of the reconstructed leg (20). Contralateral injury risk needs to be a consideration throughout rehabilitation to ensure sufficient overall function bilaterally as limb symmetry index alone can underestimate function (21), and the contralateral limb has been shown to detrain from one to five years after reconstruction (22).

Fear of re-injury was reported as a main limiting factor in an individual's ability to complete their rehabilitation as recommended. Ardern et al. (2014) identified fear of re-injury as a main determinant of a successful return to sport (4). Fear of re-injury was also the most commonly reported barrier to rehabilitation in a review of qualitative studies on ACL rehabilitation (18). The design of appropriate rehabilitation programs to facilitate a graded exposure to activities to reduce the fear associated with athletic movements should be a key focus for rehabilitation providers (23). Appropriate exercise exposure has demonstrated an improvement in psychological readiness (24), while it has also been shown that there is no link between physical function and psychological readiness (25) and therefore needs to be assessed independently.

The length and commitment of rehabilitation were also reported as a significant barrier by one in five respondents. This highlights the importance of rehabilitation providers setting realistic expectations early in rehabilitation to prepare the patient adequately for the long rehabilitation journey ahead $(26,27)$. Interestingly, motivation to complete rehabilitation was not consistently reported as a main barrier despite previous research demonstrating it as a major limiting factor for patients (12). This may be due to a selection bias as participants who were motivated to complete the survey may be naturally more motivated to invest time in rehabilitation. The majority of respondents had ongoing symptoms, which they reported as a reason they found it hard to complete their rehabilitation as prescribed. 
Consistent with previous literature, the results demonstrated the importance of the rehabilitation provider in facilitating rehabilitation (12). This includes a strong therapeutic alliance, regular assessments and goal setting, providing sports specific enjoyable rehabilitation and supportive information with consideration of financial limitations such as insurance coverage, to guide the patient throughout the rehabilitation journey.

311 The effect of a higher frequency of supervised rehabilitation, particularly in the later phases of rehabilitation is a particular area of note. Respondents reported a gradual reduction in rehabilitation frequency as rehabilitation progressed. From six months post-operation patients are rarely seeing or not seeing their rehabilitation provider, despite it being the optimal time to address post-operative deficits before return to sport (28-30). A decrease in contact between patient and physiotherapist as function improves has been reported in a survey of 223 Australian physiotherapists (31) indicating decreased contact may not have been patientdriven. A recent scoping review reported that the effect of frequency on rehabilitation outcome was unclear; therefore, further investigation into the effects of decreasing contact is warranted (12).

The reported duration of supervised rehabilitation is very encouraging, as a longer duration of supervised rehabilitation is associated with a greater likelihood to meet discharge criteria, improved functional capacity and return to sport (12). In this cohort, $95.7 \%$ of respondents attended rehabilitation over the first six months, and $78.9 \%$ of respondents completed rehabilitation through to nine months post-operative. al. (2018) (8), this seems essential, as rehabilitation in line with evidence-based guidelines has been reported to improve outcomes (8). It is likely that if patients attend rehabilitation 
sessions but are not provided rehabilitation of sufficient intensity to address post-operative deficits, then the frequency and duration of rehabilitation would be less important than the quality of the rehabilitation provided (32).

\section{Sports participation and outcomes}

333 Only $43.4 \%$ of respondents returned to their previous level of sport, which is substantially 334 lower than previous research (4). This is despite $86.5 \%$ of respondents reporting they aimed to return to their previous level of sport prior to surgery. Return to sport (86\%) was consistent with Ardern et al. (2014), who reported $81 \%$ return to some form of knee strenuous sport in a similar population. A transition to a lower level of knee strenuous sport and frequency of participation was seen across the cohort mostly attributable to those performing the most strenuous sports, reducing their sports participation.

Knee related issues were provided as the reason for not returning to previous level of sport in $67-78 \%$ of respondents, which links to the reported high levels of fear of re-injury and ongoing symptoms post-reconstruction in this cohort. This may also be the reason for the transition to a lower level of knee strenuous sport and frequency of participation. Further investigation into the reasons why individuals do not return to sport can provide further insight into the true return to sport rates by adjusting values to account for those that reduce or cease participation due to reasons not associated with their knee (22-33\% in this cohort).

Increased research and opinion suggest that delaying return to sport for 9-12 months postoperation is necessary to decrease re-injury rates (33). Only $12 \%$ of respondents returned prior to 9 months. Expectations set before surgery were consistent with respondent's eventual return to sport dates. Therefore, it may be that worries regarding returning too early are less of a concern if the appropriate advice is provided to patients. Focusing on achieving return to sport criteria in a symptom free knee should be the major focus for clinicians (2). A shared 
decision-making model is advocated in return to sport decision making (34) and supported by responses in this study. As the physiotherapist reportedly plays a key role in the decision, they can help the individual facilitate the appropriate discussions with other members of the multidisciplinary team.

\section{Exploratory Analysis}

The exploratory analysis provided preliminary evidence that patients who reported fewer barriers to rehabilitation and a longer duration of supervised rehabilitation are more likely to achieve a faster return to sport, have a greater likelihood to return to their previous level of sport, have fewer ongoing problems with the knee and have a higher rehabilitation and outcome satisfaction. If the rehabilitation provider can facilitate a rehabilitation environment to address barriers (such as fear of re-injury), encourage a longer duration of supervised rehabilitation, build a strong relationship with their patient, and support the patient through the long rehabilitation process by performing ongoing reassessments of function and goal setting, then they may be more likely to achieve favourable outcomes.

The results also support current uncertainty as to whether there is an optimal frequency of supervised rehabilitation visits and if this varies between stages of rehabilitation (12). Furthermore, patients who are experiencing high barriers will not necessarily attend rehabilitation more or less frequently or for a longer or shorter duration. It may be likely that rehabilitation providers do not vary patient attendance in response to patients' individual circumstances or barriers encountered. Younger patients and those who live in a metropolitan area appeared to attend rehabilitation more frequently and for a longer duration. Younger patients also reported a higher degree of barriers to rehabilitation. It can be hypothesised that those that live in metropolitan areas have greater access to physiotherapist care. Younger patients may experience more barriers to 
access due to cost and a bigger insult to their athletic identity (35). It may also be likely that younger individuals attend more frequently and longer due to factors not associated with their knee, such as fewer family and work commitments.

This study has several limitations. The survey itself had not been previously validated but was created using an established methodology (13). The reliability of key questions in the survey was tested through the use of the Cronbach Alpha score. The respondents of the survey were predominately from Australia, which limits the applicability of results to other countries due to variations in the delivery of health care services. The survey was completed by adults only so results cannot be generalised to the paediatric or adolescent population. While we reported on characteristics of rehabilitation and return to sport outcomes, we did not include any questions on the content of the rehabilitation or the level of competition of the participants. Future research studies may also benefit from adding injury mechanism to see if fear of reinjury is greater if the injury occurred while participating in the individuals preferred sport. The link to access the survey did not require a respondent specific login; therefore leaving the survey open to invalid responses. Through IP address screening and time to completion, check the risk of invalid response should have been reduced. The responses are influenced by recall or reporting bias and the individual's interpretation of terms and questions within the survey. The 6-step process in the development of the survey aimed to mitigate this as much as feasible (13). Responses were collected between March and July 2020 during the Covid-19 pandemic when sport participation ceased. Due to the demographics of the participants in the survey, inclusion criteria and the majority of questions pertaining to the rehabilitation experience we believe that the pandemic was unlikely to have a significant effect on the responses given.

400 Finally, the exploratory nature of the analyses provides interesting insights into associations between various categorical variables, but they do not provide evidence of any causation. 
However, the results do provide scope for further research into the factors which influence rehabilitation adherence and participation and the link to achieving a successful outcome for patients.

This survey provides insight into the state of rehabilitation practices and adult patient's perspective on the key barriers to and facilitators of $A C L$ rehabilitation adherence and participation and their relationship to patient outcomes. The most important findings of this survey are that fear of re-injury, and the therapeutic relationship was the strongest factors reported by patients which influence their ability to complete rehabilitation as recommended. Further, $78.9 \%$ of respondents completed rehabilitation through to 9 months post-operative while supervised rehabilitation frequency consistently reduced across the course of the rehabilitation. We also reported a low return to previous level of sport rate of $43.4 \%$, despite $86.5 \%$ of respondents aiming to return to their previous level of sport prior to surgery.

\section{REFERENCES}

1. Montalvo AM, Schneider DK, Yut L, Webster KE, Beynnon B, Kocher MS, et al. "What's my risk of sustaining an $A C L$ injury while playing sports?" A systematic review with metaanalysis. Br J Sports Med. 2018.

421 2. van Melick N, van Cingel RE, Brooijmans F, Neeter C, van Tienen T, Hullegie W, et al. 422 Evidence-based clinical practice update: practice guidelines for anterior cruciate ligament 423 rehabilitation based on a systematic review and multidisciplinary consensus. Br J Sports Med. 424 2016;50(24):1506-15.

425 3. Culvenor AG, Barton CJ. ACL injuries: the secret probably lies in optimising 426 rehabilitation. Br J Sports Med. 2018;52(22):1416-8.

427 4. Ardern CL, Taylor NF, Feller JA, Webster KE. Fifty-five per cent return to competitive 428 sport following anterior cruciate ligament reconstruction surgery: an updated systematic 429 review and meta-analysis including aspects of physical functioning and contextual factors. $\mathrm{Br} \mathrm{J}$ 430 Sports Med. 2014;48(21):1543-52. 
5. Ware JK, Akelman M, Owens BD, Fadale PD, Hulstyn MJ, Fleming BC. Predictors of a symptomatic knee following $A C L$ reconstruction: 84 Month Follow Up. Orthopaedic Journal of Sports Medicine. 2017;5(7). 6. Paterno MV, Rauh MJ, Schmitt LC, Ford KR, Hewett TE. Incidence of second ACL injuries 2 years after primary $A C L$ reconstruction and return to sport. The American Journal of sports medicine. 2014;42(7):1567-73.

7. Beischer S, Hamrin Senorski E, Thomee C, Samuelsson K, Thomee R. Young athletes return too early to knee-strenuous sport, without acceptable knee function after anterior cruciate ligament reconstruction. Knee Surg Sports Traumatol Arthrosc. 2018;26(7):1966-74. 8. Edwards PK, Ebert JR, Joss B, Ackland T, Annear P, Buelow JU, et al. Patient Characteristics and Predictors of Return to Sport at 12 Months After Anterior Cruciate Ligament Reconstruction: The Importance of Patient Age and Postoperative Rehabilitation. Orthop J Sports Med. 2018;6(9):2325967118797575.

9. Ebert JR, Edwards P, Yi L, Joss B, Ackland T, Carey-Smith R, et al. Strength and functional symmetry is associated with post-operative rehabilitation in patients following anterior cruciate ligament reconstruction. Knee Surg Sports Traumatol Arthrosc. 2018;26(8):2353-61.

10. Filbay SR, Ackerman IN, Russell TG, Crossley KM. Return to sport matters-longer-term quality of life after ACL reconstruction in people with knee difficulties. Scand J Med Sci Sports. 2017;27(5):514-24.

11. Grindem H, Engebretsen L, Axe M, Snyder-Mackler L, Risberg MA. Activity and functional readiness, not age, are the critical factors for second anterior cruciate ligament injury - the Delaware-Oslo ACL cohort study. Br J Sports Med. 2020.

12. Walker A, Hing W, Lorimer A. The Influence, Barriers to and Facilitators of Anterior Cruciate Ligament Rehabilitation Adherence and Participation: a Scoping Review. Sports Medicine - Open. 2020;6(1):32.

13. Artino Jr AR, La Rochelle JS, Dezee KJ, Gehlbach H. Developing questionnaires for educational research: AMEE Guide No. 87. Medical teacher. 2014;36(6):463-74.

14. Kelley K, Clark B, Brown V, Sitzia J. Good practice in the conduct and reporting of survey research. International Journal for Quality in health care. 2003;15(3):261-6. 15. Rambaud AJM, Ardern CL, Thoreux P, Regnaux JP, Edouard P. Criteria for return to running after anterior cruciate ligament reconstruction: a scoping review. $\mathrm{Br} J$ Sports Med. 2018;52(22):1437-44.

16. Grindem H, Eitzen I, Snyder-Mackler L, Risberg MA. Online registration of monthly sports participation after anterior cruciate ligament injury: a reliability and validity study. British Journal of sports medicine. 2014;48(9):748-53.

17. Paterno MV, Schmitt LC, Thomas S, Duke N, Russo R, Quatman-Yates CC. Patient and Parent Perceptions of Rehabilitation Factors That Influence Outcomes After Anterior Cruciate Ligament Reconstruction and Clearance to Return to Sport in Adolescents and Young Adults: A Qualitative Investigation. The journal of orthopaedic and sports physical therapy. 2019:1-35. 18. Anderson MJ, Browning WM, 3rd, Urband CE, Kluczynski MA, Bisson L. A Systematic Summary of Systematic Reviews on the Topic of the Anterior Cruciate Ligament. Orthop J Sports Med. 2016;4(3):2325967116634074.

19. Barber-Westin S, Noyes FR. One in 5 Athletes Sustain Reinjury Upon Return to HighRisk Sports After ACL Reconstruction: A Systematic Review in 1239 Athletes Younger Than 20 Years. Sports Health. 2020:1941738120912846.

20. Wright RW, Magnussen RA, Dunn WR, Spindler KP. Ipsilateral graft and contralateral $A C L$ rupture at five years or more following $A C L$ reconstruction: a systematic review. J Bone Joint Surg Am. 2011;93(12):1159-65. 

Function After Anterior Cruciate Ligament Injury. The journal of orthopaedic and sports physical therapy. 2017;47(5):334-8.

22. Patterson BE, Crossley KM, Perraton LG, Kumar AS, King MG, Heerey JJ, et al. Limb symmetry index on a functional test battery improves between one and five years after anterior cruciate ligament reconstruction, primarily due to worsening contralateral limb function. Phys Ther Sport. 2020;44:67-74.

23. Ardern CL. Anterior Cruciate Ligament Reconstruction-Not Exactly a One-Way Ticket Back to the Preinjury Level: A Review of Contextual Factors Affecting Return to Sport After Surgery. Sports Health-a Multidisciplinary Approach. 2015;7(3):224-30.

24. Meierbachtol A, Yungtum W, Paur E, Bottoms J, Chmielewski TL. Psychological and Functional Readiness for Sport Following Advanced Group Training in Patients With Anterior Cruciate Ligament Reconstruction. The journal of orthopaedic and sports physical therapy. 2018;48(11):864-72.

25. O'Connor RF, King E, Richter C, Webster KE, Falvey EC. No Relationship Between Strength and Power Scores and Anterior Cruciate Ligament Return to Sport After Injury Scale 9 Months After Anterior Cruciate Ligament Reconstruction. Am J Sports Med. 2020;48(1):78-84. 26. DiSanti J, Lisee C, Erickson K, Bell D, Shingles M, Kuenze C. Perceptions of Rehabilitation and Return to Sport Among High School Athletes With Anterior Cruciate Ligament Reconstruction: A Qualitative Research Study. The journal of orthopaedic and sports physical therapy. 2018;48(12):951-9.

27. Sonesson S, Kvist J, Ardern C, Osterberg A, Silbernagel KG. Psychological factors are important to return to pre-injury sport activity after anterior cruciate ligament reconstruction: expect and motivate to satisfy. Knee Surg Sports Traumatol Arthrosc. 2017;25(5):1375-84.

28. Krolikowska A, Czamara A, Reichert P. Between-Limb Symmetry during Double-Leg Vertical Hop Landing in Males an Average of Two Years after ACL Reconstruction is Highly Correlated with Post-operative Physiotherapy Supervision Duration. Appl Sci-Basel. 2018;8(12):19.

29. Krolikowska A, Sikorski L, Czamara A, Reichert P. Effects of Postoperative Physiotherapy Supervision Duration on Clinical Outcome, Speed, and Agility in Males 8 Months After Anterior Cruciate Ligament Reconstruction. Medical science monitor : international medical journal of experimental and clinical research. 2018;24:6823-31.

30. Krolikowska A, Sikorski L, Czamara A, Reichert P. Are the knee extensor and flexor muscles isokinetic parameters affected by the duration of post-operative physiotherapy supervision in patients eight months after $A C L$ reconstruction with the use of semitendinosus and gracilis tendons autograft? Acta Bioeng Biomech. 2018;20(4):89-100.

31. Ebert JR, Webster KE, Edwards PK, Joss BK, D'Alessandro P, Janes G, et al. Current perspectives of Australian therapists on rehabilitation and return to sport after anterior cruciate ligament reconstruction: A survey. Phys Ther Sport. 2019;35:139-45.

32. Krolikowska A, Czamara A, Szuba L, Reichert P. The Effect of Longer versus Shorter Duration of Supervised Physiotherapy after ACL Reconstruction on the Vertical Jump Landing Limb Symmetry. Biomed Res Int. 2018;2018:7519467.

33. Nagelli CV, Hewett TE. Should Return to Sport be Delayed Until 2 Years After Anterior Cruciate Ligament Reconstruction? Biological and Functional Considerations. Sports Med. 2017;47(2):221-32.

34. Ardern CL, Glasgow P, Schneiders A, Witvrouw E, Clarsen B, Cools A, et al. 2016 Consensus statement on return to sport from the First World Congress in Sports Physical Therapy, Bern. British Journal of Sports Medicine. 2016;50(14):853-64.

35. Brewer BW, Cornelius AE, Van Raalte JL, Petitpas AJ, Sklar JH, Pohlman MH, et al. AgeRelated Differences in Predictors of Adherence to Rehabilitation After Anterior Cruciate Ligament Reconstruction. Journal of athletic training. 2003;38(2):158-62. 
